\title{
Introduction to the Special Section: The Puzzle of Sexual Orientation: What Is It and How Does It Work?
}

\author{
Paul L. Vasey ${ }^{1}$
}

Published online: 16 December 2016

(C) Springer Science+Business Media New York 2016

In the early 1990s, there was a groundswell of interest in the biology of sexual orientation. Simon LeVay had published his now classic study in Science demonstrating that brain structure varied in males according to sexual orientation (LeVay, 1991). Two years later, Dean Hamer and his group published research in the same journal indicating that male sexual orientation had a genetic component (Hamer, Hu, Magnuson, Hu, \& Pattatucci 1993). The public was hungry for more information, but the science of sexual orientation was in its infancy; many more questions existed than answers. Fascination with this topic could be mixed with equal doses of suspicion and outright hostility depending on one's political leanings. This could come from both outside academia and from within, from those with political leanings toward the right and the left. Not surprisingly, support to enable research on the biology of sexual orientation was meager.

It was in this context that Lee Ellis decided to host the first International Behavioral Development Symposium on the Biological Basis of Sexual Orientation, Gender Identity, and SexTypical Behavior in 1995 (Ellis \& Ebert, 1997, 1998). The meeting took place on the campus of Minot State University in North Dakota and drew many of the world's leading sex researchers. So successful was this first effort that Lee went on to host two more symposia in 2000 (Zucker, Ellis, Bailey, \& Blanchard 2002) and 2005 (Zucker, 2008). I first attended in 2000 , and I can clearly remember senior scholars sitting on the edge of their seats in rapt attention as they took in cutting-edge research presentations. Many of these presentations were by up-and-coming graduate students who are now established and respected researchers

Paul L. Vasey

paul.vasey@uleth.ca

1 Department of Psychology and Neuroscience, The University of Lethbridge, 4401 University Drive, Lethbridge, AB T1K 3M4, Canada themselves. The energy, excitement, engagement, and collegiality I experienced at the Minot meetings were really something special. It was commonplace to hear participants say that these meetings were the best they had ever attended. Not surprisingly, invitations were highly coveted and grew evermore so with each meeting.

In 2005, anticipating his retirement, Lee had no desire to see the symposium disappear as a historical footnote; he was nonetheless ready to pass the organizational responsibilities for the meeting on to others. So, in 2010, Paul Vasey, Martin Lalumière, and Kelly Suschinsky (at the time, a graduate student of Martin's) hosted the Puzzle of Sexual Orientation Meeting at the University of Lethbridge in Alberta, Canada (Vasey \& Lalumière, 2012). I suspect that our location had a lot to do with Lee's decision to pass responsibility for the meeting onto us. Like Minot, Lethbridge is a small, relatively isolated city on the North American prairies. With very few "bright lights" and no "big city" to speak of, participants turned to each other for engagement, rather than outward. I strongly believe that this has been key to the success of the meetings. It probably didn'thurt that, in keeping with tradition, everyone bunks in the same dorm and shares all their meals together.

I wanted to ensure that the 2015 gathering was small and intimate. Ifelt it was important that speakers were allotted a substantial amount of time at the podium, so that they could really dig into substantive issues that arose from their research. Outside of this, I aimed to maximize the time attendees had for interacting with each other. Another priority was to create a welcoming space for young sexual orientation researchers and, in this regard, I am very happy to report that graduate student attendance at the 2015 meeting (July 21-24) was way up from 2010. I also felt it was important to heed the call from funding agencies to actively engage in knowledge translation with the public. Consequently, the journalist, Neil Swidey, was invited to attend, which resulted in a Boston Globe article about the meeting (Swidey, 2015). Lori Brotto also wrote about the meeting for the Globe and Mail 
(Brotto, 2015), a major Canadian newspaper. Several attendees "live-Tweeted" about the talk and poster presentations and these tweets were later"storified" by Michael Seto (https://storify.com/ MCSeto/puzzles-of-sexual-orientation-2015)_a first for our meetings. species, and activities. Astute readers will note that Bruce Rind proposed the existence of an additional dimension-passive/ active-in his commentary on Seto's article. Building on Bogaert's (2012) notion of autochorissexuality, Morag Yule and her colleagues propose a further dimension: subjectivity/

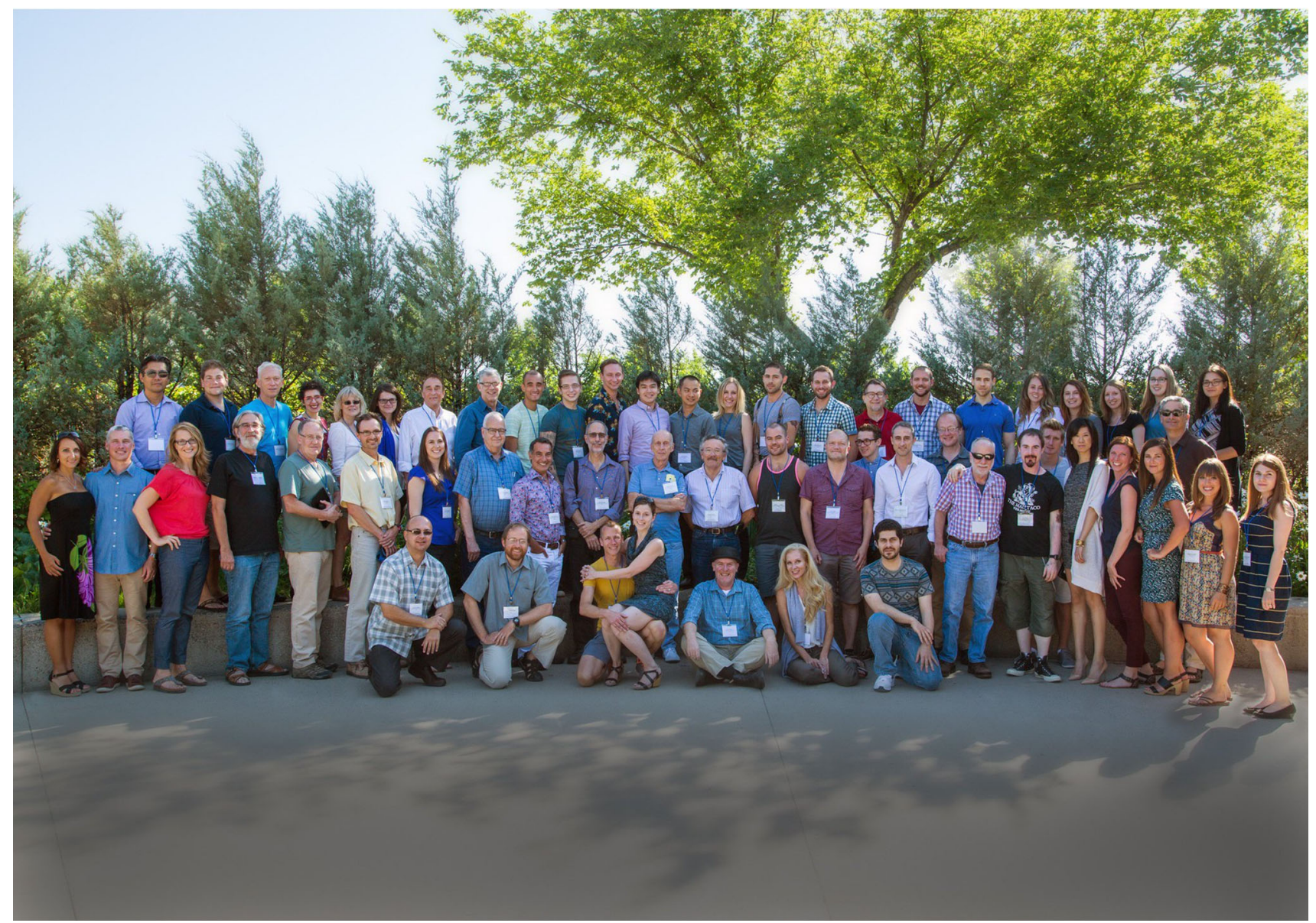

Photograph Participants at The Puzzle of Sexual Orientation Conference 2015 (Lethbridge, Alberta, Canada). Back row Michael Seto, David Moskowitz, Ritch Savin-Williams, Lisa Diamond, Heather Hoffmann, Malvina Skorska, Lee Ellis, Matthew Grober, Francisco Gómez, Matthew Stief, Ryan Mallard, Keven Hsu, Erik Wibowo, Lanna Petterson, Theodore Semon, Scott Semenyna, Sergio Pellis, Doug VanderLaan, Nicholas Rule, Skye Stevens, Kelly Babchishin, Jackie Huberman, Amanda Timmers, Robyn Jackowich. Middle row Lori Brotto, Martin Lalumière, Meredith Chivers, Richard Wassersug, J. Michael Bailey, Anthony Bogaert, Lesley Roberts, Thomas Johnson,

One of my major goals for the Lethbridge meetings has been to nudge participants to think more deeply about what exactly was meant by the term "sexual orientation." Does it just refer to attraction to men or women or both, or does it encompass something more? Michael Seto's Target Article, "The Puzzles of Male Chronophilias," in this issue provides but one example of where such "out of the box" thinking led participants during the 2015 meetings. He suggests that sexual orientation is multidimensional and involves attraction to a range of stimulus parameters, including gender, age, self/otherness, living/nonliving,
James Cantor, Richard Lippa, Simon LeVay, Marc Breedlove, Matthew Bramble, Erin Vilain, Corbin Chenger (behind), Eduard Playà, Alan Sanders (behind), Ken Zucker, Jim Pfaus, Lucas Court (behind), Debra Soh, Morag Yule, Samantha Dawson, Neil Swidey, Megan Sawatsky, Marie-Andrée Légère. Front row Anthony Hoskin, Jean-Baptiste Leca, Gerulf Rieger, Kelly Suschinsky, Paul Vasey, Katherine Frank, Heitor Fernandes. Note: Due to a transient physical health problem, Ray Blanchard was unable to attend the meeting. Photo Credit: Andrew Hurley

non-subjective. Michael Bailey and his students emphasized the importance of sexual aversion in structuring sexual orientation.

Bisexuality and emergent topics arose as central points of discussion during the 2015 meeting. Is sexual orientation in men overwhelmingly categorical or does it fall out along a continuum? Just how sexually fluid are women (and men)? What is the relationship between sexual arousal and sexual attraction? How can we best measure sexual orientation? Many of the articles in this special section make important 
attempts at tackling these thorny issues. Above and beyond all this, I'm extremely pleased that a number of researchers were able to flesh out the cross-cultural contributions in this special section, with invaluable data, including Raymond Hames and his students, as well as Matthew Stief.

I am doubly proud of this special section because it not only contains the proceedings of the 2015 Puzzle of Sexual Orientation Meeting, but it represents the first issue of Archives in which the journal's new Target Article feature is being formally launched. It is my hope that the Target Articles will serve as a lively forum for addressing controversial issues in sex research. Each Target Article is followed by invited commentaries from a select number of experts. The Target Article author(s) then respond, in turn, to these commentaries. Archives readers should look for more Target Articles in the coming months from other Puzzle of Sexual Orientation attendees, including Lori Brotto and Morag Yule, Meredith Chivers, and Marc Breedlove.

There are many individuals and groups that I have to thank and without whom the 2015 Puzzle of Sexual Orientation meeting would not have been a reality. Various units at the University of Lethbridge, including the Offices of the President, the Vice-President Academic, the Vice-President Research, and the Dean of Arts \& Science, generously contributed financial support for the 2015 meeting. In particular, I would like to thank Drs. Mike Mahon, Andrew Hakin, Lesley Brown, and Craig Cooper for financial contributions that helped to make the workshop a success. I am exceedingly grateful that the University of Lethbridge has extended such generous support for sex research, not the least of which was a Board of Governors Research Chair that I was honored with around the time the 2015 meeting took place. I am also very grateful to the Social Sciences and Humanities Research Council (SSHRC) of Canada which awarded a generous Connection Grant to support our meeting. Canada is certainly a great place to be a sex researcher. By readily pledging to publish the proceedings of the meeting in a special issue of the Archives, the Editor, Ken Zucker, once again provided important leverage in my pursuit of funding. Drs. Lee Ellis and Thomas W. Johnson donated substantial personal funds to support the meeting. Their generosity is humbling. The always forward-thinking John Sylla and the American Institute of Bisexuality also provided financial support for the meeting for which I am extremely thankful. Rebecca Anweiler graciously allowed us to use her wonderful artwork ("Learning How to Use and Control Heat") for the cover of our program booklet and Mary Kavanagh took the time to provide a description of the work. Lesley Roberts created the Puzzles logo that appeared in the workshop program booklet. Many individuals offered varying levels of administrative and logistical support that helped ensure the meeting ran smoothly, including Karen Blair, Laurel Corbiere, Heather Hoffmann, Simon LeVay, Kathy MacFarlane, Ryan Mallard, Richard Westlund, and Gabe Yanicki. Extra special thanks goes to Erin Crane and Leanne Wehlage-
Ellis who are both remarkable women. I want to thank my students, Lanna Petterson, ScottSemenyna, Lucas Court, Francisco Gómez, and Corbin Chenger, who helped ensure that the visiting participants' experience of southern Alberta was a memorable one well into the wee small hours of the night, long after I had to beg off for bed.

The 2015 meeting was co-hosted with Drs. Kelly Suschinsky and Jean-Baptiste Leca. This special section was co-edited with Kelly and Dr. Doug VanderLaan. ${ }^{1}$ Thank you all for your support, your collegiality, and for doing interesting research that makes the world of sexology a better place!

I think the contents of this special section bear witness to the fact that the 2015 meeting was a resounding success. It was truly a privilege to be able to host so many esteemed colleagues for whom I have the deepest respect. I sincerely thank all the participants for making the trek to Lethbridge. During the 2015 meeting, it became clear that there are many puzzles that remain to be solved for many sexual orientations beyond the standard issue gay, bi, and straight. I look forward to hearing about the progress that has been made in solving these puzzles of sexual orientations at the next meeting in 2020 .

\section{References}

Bogaert, A. F. (2012). Asexuality and autochorissexualism (identityless sexuality). Archives of Sexual Behavior, 41, 1513-1514.

Brotto, L. A. (2015). Sexual orientation is more complex than straight, gay or bisexual. Globe and Mail. Retrieved from http://www. theglobeandmail.com/life/health-and-fitness/health-advisor/sexualorientation-is-much-more-complex-than-straight-gay-or-bisexual/ article26053887/

Ellis, L., \& Ebert, L. (Eds.). (1997). Sexual orientation: Toward biological understanding. Westport, CT: Praeger.

Ellis, L., \& Ebert, L. (Eds.). (1998). Males, females, and behavior: Toward biological understanding. Westport, CT: Praeger.

Hamer, D. H., Hu, S., Magnuson, V. L., Hu, N., \& Pattatucci, A. M. (1993). A linkage between DNA markers on the X chromosome and male sexual orientation. Science, 261, 321-327.

LeVay, S. (1991). A difference in the hypothalamic structure between heterosexual and homosexual men. Science, 253, 1034-1037.

Swidey, N. (2015). What makes people gay (an update). Boston Globe. Retrieved from https://www.bostonglobe.com/magazine/2015/ 08/22/what-makes-people-gay-update/8Mos2MXHvX5JsxP7AzW 9RJ/story.html

Vasey, P. L., \& Lalumière, M. L. (2012). Guest Editors' Introduction to the Special Section on The Puzzle of Sexual Orientation: What Is It and How Does It Work? Archives of Sexual Behavior, 41, 11-12.

Zucker, K. J. (2008). Special issue: Biological research on sex-dimorphic behavior and sexual orientation. Archives of Sexual Behavior, 37, 1.

Zucker, K. J., Ellis, L., Bailey, J. M., \& Blanchard, R. (2002). Guest Editors' Introduction: Biological research on sex-dimorphic behavior and sexual orientation. Archives of Sexual Behavior, 31, 7.

\footnotetext{
${ }^{1}$ All articles appearing in the special section were peer reviewed. None of the Co-Editors were involved in the peer-review process for their own papers. Ken Zucker acted as the Editor for all of the papers on which I was a co-author.
} 